\title{
A Structured Comparison of the Service Offer and the Service Supply Chain of Manufacturers Competing in the Capital Goods and Durable Consumer Goods Industries
}

\author{
Donatella Corti and Alberto Portioli-Staudacher \\ Politecnico di Milano \\ Department of Management, Economics and Industrial Engineering, \\ P.za Leonardo daVinci, 32 - 20133 Milano, Italy \\ donatella.corti@polimi.it, alberto.portioliepolimi.it
}

\begin{abstract}
The increasing importance of the service offer for manufacturing companies has lead to the development of different service chains and service package in different industries. The main aim of this paper is to provide a structured comparison of the service offer and configuration in the capital goods and durable consumer goods industries. Even though the paper is mainly of a conceptual nature, the discussion is based on empirical findings collected. Main trends of the service provision within the corresponding supply chains are also highlighted and some guidelines for the service development are introduced.
\end{abstract}

Keywords: after-sales services, capital goods, durable consumer goods, aftersales supply chain.

\section{Introduction}

Since it is more and more difficult to differentiate products on the basis of technological superiority only and margins associated to the product sell are decreasing, services have become a possible source of competitive advantage (Wise and Baumgartner, 1999; Goffin, 1999; Cohen et al., 2006; Gebauer, 2008). The strategic consideration of services in manufacturing sectors is quite a recent phenomenon and the relevance of services in this context is expected to increase further in the next years, nonetheless the adoption of a service orientation is not a trivial task (Mathieu, 2001; Oliva and Kallenberg, 2003) and the literature focused on the servitised supply chains is still scarce; much empirical research in this area is thus called for (see for example Johnson and Mena, 2008).

The increasing importance of the service offer is common to many manufacturing sectors, yet service needs have evolved over the last years following different paths depending on the product's features (e.g. value and volume of products sold, degree of customization, etc.) and the type of customer (industrial or consumer).

The aim of this paper is twofold. On the one hand, a structured comparison of the service offer and configuration in the capital goods and durable consumer goods 
industries is carried out in order to indentify drivers that lead to different configuration choices. Secondly, main trends of the service provision within the corresponding supply chains are highlighted and some guidelines for the service development are introduced.

Even though the paper is mainly of a conceptual nature, the discussion is based on empirical findings gathered by authors in different sectorial analysis carried out in the Italian market. In particular, the main reference for this paper is an empirical research that involved 21 companies operating in the consumer electronics (11 companies) and in the capital goods (10 companies) markets. The sampled companies have been selected in such a way all the main roles of the supply chain have been investigated. For both industries, at least one actor with the following roles has been analyzed: spare parts producer, OEM, wholesaler, dealer and assistance center. Data have been collected by means of face-to-face interviews based in a structured questionnaire different for each role.

\section{Capital Goods and Durable Consumer Goods: Main Differences}

It is a basic assumption of this paper that different requirements in terms of service management can be traced back to differences in terms of product use and nature of the supplier-customer relationship. The reason why it has been decided to focus also on the customer type is due to the central role the customer has in the service offering of any industry. In fact, it has been stated in several research (see for example Oliva and Kallenberg, 2003; Gebauer et al., 2008) that the offer of services by a manufacturing company requires the adoption of a customer oriented perspective according to which strategic decisions are made starting from the understanding of customer needs and requirements. As a consequence, not only the type of product, but also the type of customer, should drive the development of a service strategy that could strengthen the competitive position.

Part of the reasoning that is being presented in this paper could have a wider application and could be extended to the business-to-business (B2B) and business-toconsumer (B2C) markets. Nonetheless, due to the source of empirical data the discussion is based on, the reference industries are capital goods (for the B2B world) and the durable consumer electronics goods (for the B2C world). More specifically, in this paper capital goods are those machines and equipments that becomes part of the production process of the customer (textile machines, woodworking machines, machines tools, etc.).

\subsection{Differences in Terms of Product Characteristic}

Table 1 summarizes for each category of products the main features that have an influence on the after-sales requirements as are also introduced, for example, by Armistead and Clark (1992) and Legnani et al. (2009). 
Table 1. Comparison of the features of the product and its use in the capital goods industry vs the consumer electronics industry

\begin{tabular}{|l|c|c|}
\hline \multicolumn{1}{|c|}{ Characteristic } & $\begin{array}{c}\text { Consumer } \\
\text { electronics goods }\end{array}$ & Capital goods \\
\hline Lifecycle & Short & Long \\
\hline $\begin{array}{l}\text { Degree of } \\
\text { customization }\end{array}$ & Usually very low & Medium- high \\
\hline $\begin{array}{l}\text { Frequency of contacts } \\
\text { with supplier during the } \\
\text { lifecycle }\end{array}$ & Very low & Medium-high \\
\hline $\begin{array}{l}\text { Level of customer's } \\
\text { product expertise }\end{array}$ & Usually fairly low & Usually fairly high \\
\hline Cost of ownership & Low-medium & High \\
\hline $\begin{array}{l}\text { No. of customers/ } \\
\text { installed base }\end{array}$ & Usually high & Usually low \\
\hline Level of response time & High/fixed & Low/variable \\
\hline $\begin{array}{l}\text { Replace costs/repair } \\
\text { costs }\end{array}$ & Low & High \\
\hline Cost of failure & Relatively low & Relatively high \\
\hline
\end{tabular}

\subsection{Differences in Terms of After-Sales Network Configuration}

The sale and the after-sales networks in the two analyzed industries often differ from each other. In this context it is of interest a detailed analysis of the after-sales channel. In most cases the after-sales channel is not the same as the sale channel: different actors are involved and also the responsibilities are different.

The most evident difference between the B2B and a B2C network is the "width" of the channel: where the network has to be as widespread as possible to reach the high number of customers in the B2C channel, in the B2B context a few highly specialized actors form the after-sales channel. The customer proximity is an essential element that influences the customer satisfaction for consumer goods, while an industrial customer is mainly interested in having the problem fixed as soon as possible. The limited number of customers is another reason that does not make economically feasible to set up of a widespread assistance network for industrial products. The number of intermediaries is limited for the capital goods market not only because the number of customers is low, but also because the level of expertise needed to carry our assistance activities is fairly high and only the supplier has the knowledge to fix problems. At this regard, it has also to be remembered that industrial goods are often customized and it is not possible to identify standard procedures that could be transferred to operators along the after-sales network as it is the case for some consumer products.

Figure 1 shows a generalized configuration of an after-sales network for servicing consumer products. It is referred to the Italian market, since for consumer goods the after-sales network is different depending on the market (like it is the sale channel). The interface for the customer is merely the producer and this means that customer satisfaction is heavily dependent upon intermediaries that most of the time are not owned by the producer (this is not only the case of consumer electronics, but also home appliances and automotive sectors). When a problem arise with the use of a consumer product, the end user can decide either to contact the dealer where the product was bought or one assistance center. 


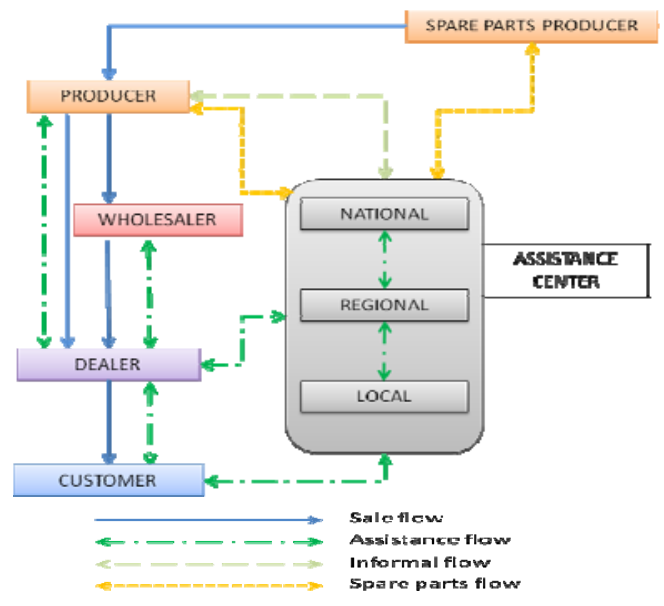

Fig. 1. Consumer electronics after-sales supply chain

The typical configuration of the after-sales supply chain for industrial goods is shown in Figure 2. The producer is the focal point who deals direclty with most of the other actors involved, including the customer. Unlike for the consumer goods aftersales chain, in this case the network could cover an internationl area since in many cases customers are spread all over the world, whilst the production could be in a single country. The distance between the customer and the manufacturer along with the limited number of specilized technicians who are able to carry out assistance activities, make it necessary for the producer to rely on local parterns for servicing local markets. The most common solution is the establishment of a local representative office that coordinates both the sales and the after-sales activities. Another reason why the direct contact between the supplier and the customer is relevant in this context, is the importance of the pre-sale services. The higher the level of customization

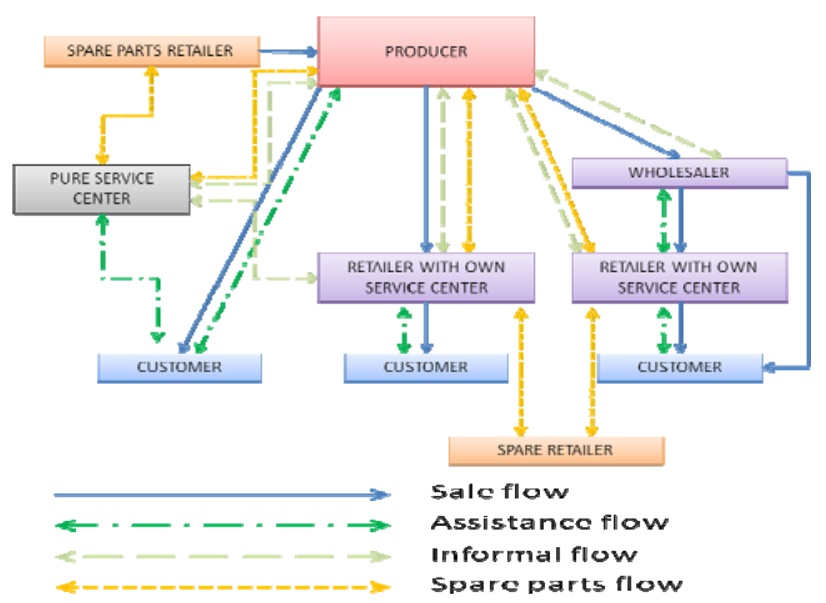

Fig. 2. Capital goods after-sales supply chain 
Table 2. After-sales supply chain: criticalities of different roles in the consumer goods and capital goods industries

\begin{tabular}{|c|c|c|}
\hline & \multicolumn{2}{|c|}{ MARKET } \\
\hline $\begin{array}{l}\text { PRODUCER } \\
\text { Interaction with customer } \\
\text { Services portfolio } \\
\text { Specific features }\end{array}$ & $\begin{array}{c}\text { Consumer electronics } \\
\text { Indirect } \\
\text { Traditional } \\
\text { Large companies external } \\
\text { processes, while they main }\end{array}$ & $\begin{array}{l}\text { Capital goods } \\
\text { Direct/Indirect } \\
\text { Wider } \\
\text { the execution of operative } \\
\text { n the control on the network }\end{array}$ \\
\hline $\begin{array}{l}\quad \text { WHOLESALER } \\
\text { Interaction with customer } \\
\text { Services portfolio } \\
\text { Specific features }\end{array}$ & $\begin{array}{c}\text { Consumer electronics } \\
\text { Indirect } \\
\text { Traditional } \\
\text { Full intermediary role }\end{array}$ & $\begin{array}{c}\text { Capital goods } \\
\text { Direct } \\
\text { Value added services } \\
\text { Innovative role }\end{array}$ \\
\hline $\begin{array}{l}\text { SERVICE CENTERS } \\
\text { Interaction with customer } \\
\text { Services portfolio } \\
\text { Specific features }\end{array}$ & $\begin{array}{c}\text { Consumer electronics } \\
\text { Direct/Indirect } \\
\text { Specialized } \\
\text { Focus on capillarity } \\
\text { Multi-brand } \\
\text { Hierarchical organization }\end{array}$ & $\begin{array}{c}\text { Capital goods } \\
\text { Direct } \\
\text { Wide } \\
\text { Focus on customer closeness } \\
\text { Multi-brand/Mono-brand } \\
\text { Informal interrelationships }\end{array}$ \\
\hline $\begin{array}{l}\text { RESELLERS } \\
\text { Interaction with customer } \\
\text { Services portfolio } \\
\text { Specific features }\end{array}$ & $\begin{array}{c}\text { Consumer electronics } \\
\text { Direct } \\
\text { No intervention } \\
\text { After-sale intermediary } \\
\text { Assistance on own sold } \\
\text { products } \\
\text { Bind to trade channel }\end{array}$ & $\begin{array}{c}\text { Capital goods } \\
\text { Direct } \\
\text { Intervention } \\
\text { Assistance on all products } \\
\text { Informal interrelationships }\end{array}$ \\
\hline $\begin{array}{l}\text { SPARE PARTS SUPPLIER } \\
\text { Interaction with customer } \\
\text { Services portfolio } \\
\text { Specific features }\end{array}$ & $\begin{array}{c}\text { Consumer electronics } \\
\text { Absent } \\
\text { Absent } \\
\text { Spare parts provisioning to } \\
\text { service centers }\end{array}$ & $\begin{array}{c}\text { Capital goods } \\
\text { Direct/Indirect } \\
\text { Wide } \\
\text { Active role within the supply } \\
\text { chain }\end{array}$ \\
\hline
\end{tabular}

of the product, the higher the need of interaction between the two parties to identify the most suitable solution for the user or to devleop an ad hoc soluton.

Even though the type of actors is similar in the two channels, there are differences in terms of nature of links, relationships and flows among the nodes of the network.

On the one hand, the B2C chain features a more hierarchical organization of the flow management that is dependent upon decisions made by the producer even though there is not direct link between the customer and the producer. On the other hand, the B2B channel is often characterised by more flexible links among different actors.

The main differences in term of roles of the same actors in the two channels are summarized in Table 2.

Another difference is the nature of the logistics flow. In the $\mathrm{B} 2 \mathrm{C}$ market the more relevant flow is the one of substitutive products, whilst the spare parts flow is being reduced over time due to the fast rate of new product introduction. Assistance center 
thus tend to minimize the spare parts stock and, in case of need, the order is placed directly to the OEM or to a spare part producer. On the contrary, in the B2B market, the spare part flow is the main one due to the product nature. The spare parts management is less critical then in the B2C channel for two reasons: the longer life cycle of components (lower risk of obsolescence) and the higher inventory turn-over index.

The focus of the improvement interventions in the logistics are thus different in the two markets: optimization of the spare parts management in the B2B market due to the high level of customization and the long life cycle; optimization of the substitutive product flow in the $\mathrm{B} 2 \mathrm{C}$ market where the degree of customization is low and the life cycle is short.

\subsection{Differences in Terms of Value Added Services}

Empirical findings show that there is a difference between what is considered to be a value added service in the two markets even though in both cases new services are of an immaterial nature (traditional services like maintenance, spare part provision are given for granted in all markets). In the B2C context (for example for the consumer electronics) technical advice, training courses, home support, software upgrade and on-line monitoring are value added service. Guarantee extension, remote assistance, customization of training and maintenance and retrofitting are among the most valued services in the B2B market. Some services that are standard for one customer type becomes value added in the other market and vice-versa.

The comparison of these findings lead to the identification of two main drivers that influence the development of additional services. They are:

- the degree of innovation embedded in the service meaning its technological content and the level of the service novelty for the particular market sector;

- the degree of service customization in terms of a company's ability to tailor the service to the customer's needs.

Companies operating in the $\mathrm{B} 2 \mathrm{~B}$ market develop the service area by customizing their value added services in order to follow the customer's requests, whereas the trend in the B2C channel is to increase the level of innovation included in the service that is standard.

\section{Discussion}

One of the main objective of the after-sales service provision is to make customers loyal. At this regard, there is a big difference between the two chains. In the B2B market, the supplier-customer relationship is more developed: product support is essential for the product use (maintenance, spare parts,...) and during the product life cycle the need for the user to contact the supplier is frequent. The direct contact with the customer and the necessity of contacts (alternative service supplier are not common) makes it easier for the supplier to establish a long-term relationship with the customer and, as a consequence, there will be a strong motivation for the user to stay with the same supplier for the next purchase.

On the contrary, in the consumer electronics market, the short life cycle of products and the presence of different substitutive products, lead the producer to find 
different ways to retain customers. A good marketing strategy is one of the available tool to reach a high number of potential customers, even though there is not the possibility to have a face-to-face relationship with them. The low value of the replace costs/repair costs ratio could prevent the customer to ask any assistance. As a consequence, it is not enough to have an excellent technical assistance, a set of innovative and additional services are needed to attract new customers and to retain the old ones.

In the capital goods market, to best tailor the service offer to the specific user, the supplier should have a deep knowledge of the operations of the customer and the effect the product-service package will have on the customer's process and performance. The different use of the product in the consumer electronics market makes this point less critical this point: the product is purchased to satisfy a personal need and there is no need for the supplier to enter the whole process use that, however, less complex.

Even though the main differences in terms of service offer and service channel configuration are dependent upon the product nature and the type of the customer, it could be interesting to identify possible guidelines to further develop the service offer trying to transfer some approaches from one market to the other.

Two main considerations can be drawn at this regard:

- Value added services: in order to fully exploit the potentialities of the service offer to improve the competitive advantage the two channels can learn something looking at the best practices in the other market. In particular, in the B2B market, an higher level of embedded technology should improve the service offer. Not only remote assistance tools are needed, but also the internet channel could be further exploited (online catalogues, online training are still scarce in this context). On the other hand, the B2C market could benefit by the introduction of an higher level of customization of service. In this case, what can be customized is the time within each intervention has to be satisfied. Considering that customers are sensible to service time and cost variation, it would be interesting to offer the same service at a different cost depending on the time the customer is willing to wait for having the problem fixed.

- Configuration of the after-sales supply chain. Starting from the capital goods market, one of the main problem is the presence of independent actors (like pure serviced center or retailers with their own service center) who can attract users at the end of the guarantee period, thus reducing the service business for the original manufacturer. As a consequence, this situation could lead to a loss of brand visibility for the producer. A possible solution could be the creation of a more widespread owned assistance network or the development of formal partnership agreements with the already existing independent service provider and retailers. The first solution is feasible only for the biggest companies whose installed base is higher (thus volume becomes a relevant parameter), while the second one can be attained by small companies as well. Always looking at the consumer electronics market, it would be useful to strengthen the service marketing. In most cases, the service is not advertised at all by the company making thus it difficult for customers to appreciate a diversified service offer.

The rigidity of the after-sales network in the consumer electronics market makes it more difficult to change the configuration of the channel. The existence of 
different actors in the capital goods channels could be a possible source of inspiration to widen the business of the assistance centers and the dealers which need to find a way to remain profitable in the future. For example, the dealers could be provided with an owned assistance center authorized for the sold products or the assistance center could increase the business by starting selling products.

Of course, a careful analysis would be need to analyze the cost/benefit trade-off associated to these possible development and further empirical analysis is needed to test their feasibility.

\section{Conclusion}

Findings show how the service offer should be organized and managed depending on the company's position in the market in order to fully exploit the potential contribution of services to the overall performance. The different configuration and level of complexity of the after-sales supply chain is also taken into consideration in order to identify how responsibilities and risks are shared among the actors in the network and how these relationships are evolving over time.

Furthermore, the cross-industry analysis is used to identify possible practices that can be transferred from one sector to another one or from one channel to the other.

This paper is a contribution to the service literature that is still fragmented and lacks of a structured comparison that can help in better understanding the key differences affecting companies service performances.

In order to improve the validity of the findings a wider empirical analysis should be needed. The conceptual framework that is derived could be easily extended to some industries like the one of home appliances that share some features with the consumer electronics. For a more generalized discussion that could be applied to the B2B and B2C markets more empirical research is needed, in particular focused on those products, like the copy machines, that can be sold in the two channels. Finally, the proposed discussion could be used as a starting point to identify specific topics that can be analyzed in depth by means of specific research project.

\section{References}

1. Armistead, C., Clark, G.: A Framework for Formulating After-sales Support Strategy. International Journal of Operation \& Production Management 11, 111-124 (1992)

2. Cohen, M.A., Agrawal, N., Agrawal, V.: Winning in the Aftermarket. Harvard Business Review 84(5), 129-138 (2006)

3. Gebauer, H.: Identifying service strategies in product manufacturing companies by exploring environment - strategy configurations. Industrial Marketing Management 37, 278-291 (2008)

4. Gebauer, H., Krempl, R., Fleisch, E., And Friedli, T.: Introduction of product-related services. Managing Service Quality 18(4), 387-404 (2008)

5. Goffin, K.: Customer support - A cross-industry study of distribution channels and strategies. International Journal of Physical Distribution and Logistics Management 29(6), 374 397 (2009) 
6. Johnson, M., Mena, C.: Supply chain management for servitised products: a multi-industry case study. International Journal of Production Economics 114, 27-39 (2008)

7. Legnani, E., Cavalieri, S., Ierace, S.: A framework for the configuration of the after-slaes service processes. Production Planning and Control 20(2), 113-124 (2009)

8. Mathieu, V.: Service strategies within the manufacturing sector: benefits, costs and partnership. International Journal of Service Industry Management 12(5), 451-475 (2001)

9. Oliva, R., Kallenberg, R.: Managing the transition from products to services. International Journal of Service Industry Management 14(2), 160-172 (2003)

10. Wise, R., Baumgartner, P.: Go downstream - the new profit imperative in manufacturing. Harvard Business Review 77(5), 133-141 (2003) 